\title{
Research on the Development Status, Influencing Factors and Support Measures of Taizhou Gazelle Companies
}

\author{
Gabriel Kwetey Tetteh, \\ Zhejiang University of Science and Technology ZUST, Zhejiang, China (Economics and Management \\ Department), Taizhou University \\ gabrieltetteh73@yahoo.com \\ Hu Yunyin, \\ Professor of Business School, Taizhou University And Tutor for External Masters of Zhejiang University of \\ Science and Technology
}

\begin{abstract}
A gazelle is a company with a rapid high-growth rate that has been increasing its revenues by at least $20 \%$ annually for four years or more, starting from a revenue base of at least $\$ 1$ million. This steady growth trend means that the company has more than doubled its revenues over a four-year period. Gazelle companies are characterized by fast sales growth, rather than their absolute size, they can range in size from small companies to very large companies, though a majority of them are on the small scale businesses. Gazelle is small company that grows rapidly, increases revenue, with big contribution to the growth of the economy", such company now has entered the high growth stage across the entrepreneurial Death Valley image of innovative companies. The short history of these companies establishes that this companies has the following features to their credit fast growth, new areas of expertise, development potential and innovative ability which are important indicators of the evaluation of a country or region of innovation and economic development vitality and core competitiveness of the region. Looking at well-known cities at home and abroad, which actively introduced various policies to boost the development of Gazelle companies, leading to the regional economic fission. In Taizhou, gazelle companies is undoubtedly the main force of innovation, entrepreneurship, and first-class business which is to adjust the structure of Taizhou, promoting and upgrading the driving force of the region. To understand the present situation of the development of Taizhou gazelle companies, to study the factors influencing the development of Gazelle companies, to learn from the policy experience of promoting the development of Gazelle companies in domestic and foreign regions or cities, to form the policy system of cultivating and supporting the Gazelle companies in Taizhou.
\end{abstract}

Keywords: Gazelle Enterprise; Development Status; Influencing Factors; Countermeasure Suggestions.

DOI: $10.7176 / \mathrm{JESD} / 11-8-02$

Publication date: April $30^{\text {th }} 2020$

\section{Introduction}

The number of Gazelle companies has increasingly become an important indicator of a country or region's innovation capacity and economic development vitality, is an important force to promote economic fission growth, the OECD will continue to track the development of Gazelle companies each year. From the concept of foreign gazelle company's definition, Ministry of Science and technology torch Survey Information System 2013-2016 data practices, combined with the actual Taizhou information on gazelle, we meet the following conditions for which a companies can to be defined as the Gazelle Company: progressive main business revenue growth rate of more than $20 \%$ in three consecutive years. For two consecutive years According to this standard, Taizhou currently has 28 gazelle companies, specifically in Table 1. 
Table 1: | Taizhou Gazelle Enterprise Catalogue

1. Zhejiang Wanglong Rail Transit Equipment Co. Ltd.

2. Zhejiang Taihong Electrical And Mechanical Co. Ltd.

3. Zhejiang Shengtai Defense Technology Co. Ltd.

4. Zhejiang Mark Transformer Co. Ltd.

5. Taizhou Jiuyi Mechanical And Electrical Co. Ltd.

6. Zhejiang Dashenya Environmental Protection Co. Ltd.

7. Zhejiang Xingxing Jianbao Co.

8. Zhejiang Haizheng Biological Materials Co. Ltd.

9. Zhejiang Tejieer Intelligent Sanitary Ware Co. Ltd.

10. Zhejiang Yihe Sanitary Ware Co. Ltd.

11. Taizhou Huangyan Albert Mould Co. Ltd.

12. Taizhou Xinli Molding Technology Co. Ltd.

13. Zhejiang Yu Too Auto Parts Manufacturing Co. Ltd.

14. Zhejiang Wangsheng Power Mechanical And Electrical Co. Ltd.

15. Zhejiang Beilide Energy Technology Co. Ltd.

16. Zhejiang Zhongyuan Railway Fittings Co. Ltd.

17. Zhejiang Hongshi Liang Group Tiantai Mountain Medicine Co. Ltd.

18. Zhejiang Advanced Communication Equipment Co. Ltd.

19. Zhejiang Youyi Medical Instrument Co. Ltd.

20. Zhejiang Xiantong Rubber \& Plastic Co.

21. Wanbangde Pharmaceutical Group Co., Ltd.

22. Zhejiang Medikai Modern Photoelectric Co. Ltd.

23. Zhejiang Luhu Automobile Co. Ltd.

24. Zhejiang Huahe Plastic Technology Co. Ltd.

25. Zhejiang Geely Automobile Research Institute Co. Ltd.

26. Zhejiang Mes Lithium Technology Co. Ltd

27. Zhejiang Rongxin Gas Meter Co. Ltd

28. Zhejiang Glory Biotechnology Co. Ltd

\section{Development Status of Taizhou Gazelle Enterprise}

\subsection{Regional Distribution Analysis}

Taizhou Gazelle Companies Regional distribution is not balanced, with most Gazelle companies in Linhai amounting to a total of 6, followed by Jiaojiang District, a total of 5, high-tech zone and Yuhuan City, respectively, 4, Luqiao district and Sanmen County no gazelle company. According to data from 2016, the number of Gazelle company in each county, total assets, main business income, high-tech products (services) income, net profit, etc., as shown in Table 2.

Table 2: Regional Distribution Analysis of Taizhou Gazelle Enterprises

\begin{tabular}{|l|l|l|l|l|l|}
\hline Numbers & $\begin{array}{l}\text { Number Of } \\
\text { Enterprises } \\
\text { (Home) }\end{array}$ & $\begin{array}{l}\text { Total Assets } \\
\text { (Million) }\end{array}$ & $\begin{array}{l}\text { Operating } \\
\text { Income } \\
\text { (Million } \\
\text { Yuan) }\end{array}$ & $\begin{array}{l}\text { High-Tech } \\
\text { Products } \\
\text { Revenue } \\
\text { (Million) }\end{array}$ & $\begin{array}{l}\text { Net Profit } \\
\text { (Million) }\end{array}$ \\
\hline Jiaojiang & 5 & 68382.5 & 51140.7 & 47329.7 & 2747.5 \\
\hline Huangyan & 3 & 63524.4 & 53432.9 & 43656.2 & 7317.7 \\
\hline $\begin{array}{l}\text { Road and } \\
\text { Bridge }\end{array}$ & 0 & $/$ & $/$ & $/$ & $/$ \\
\hline The Sea & 6 & 743765.9 & 758264.8 & 613773.4 & 45127 \\
\hline Wenling & 2 & 133042.5 & 86900.4 & 74106.3 & 20951.3 \\
\hline Yuhuan & 4 & 74587.7 & 77756.4 & 57875.7 & 5754.7 \\
\hline Rooftop & 2 & 22387.4 & 26936.5 & 22750.6 & 6843.5 \\
\hline Three. & 0 & $/$ & $/$ & $/$ & $/$ \\
\hline Xianju & 2 & 105255 & 54704.2 & 40864 & 12836.8 \\
\hline $\begin{array}{l}\text { High-Tech } \\
\text { Zone }\end{array}$ & 4 & 122059.7 & 54941.2 & 47999.7 & 4299.7 \\
\hline Total & 28 & 1333005.1 & 1164077.1 & 948355.6 & 105878.2 \\
\hline
\end{tabular}

2.2 Analysis of Key Financial Indicators

Taizhou gazelle companies in 2013 average main business income is 164.062 million yuan, 2014 average main 
business income of 124.5 million yuan, 2015 average main business income of 136.984 million yuan, 2016 average main business income of 415.742 million yuan, annual growth rate of $-24.11 \%, 10.03 \%$ and $203.50 \%$, nearly three years annual growth rate of $63.14 \%$; gazelle annual growth rate of $91.83 \%, 34.80 \%$ and $168.36 \%$, nearly three years average growth rate of $98.33 \%$. Gazelle companies in 2013 actually pay taxes and fees averagely of 10.39 million yuan, in 2014 actually pay taxes and fees average of 67.58 million yuan, in 2015 actually pay taxes and fees average of 100.246 million yuan, in fact in the past three years, the average annual growth rate was $44.27 \%$ gazelle company's new technology products (services) revenue accounted for the proportion of the main business revenue, which showed a steady growth trend in 2013, which was 67.38\%, $2014(71.66 \%) 2015(64.05 \%)$ and in 2016 is $81.47 \%$.In 2016, there are 2 gazelle companies with operating income of over 1 billion yuan, 3 companies with 5 to 1 billion yuan, 10 companies with 1 to 500 million yuan, 6 companies with 50 million to 100 million yuan, 5 companies with 10 million to 50 million yuan, and 2 companies with less than 10 million yuan. See Figure 1.

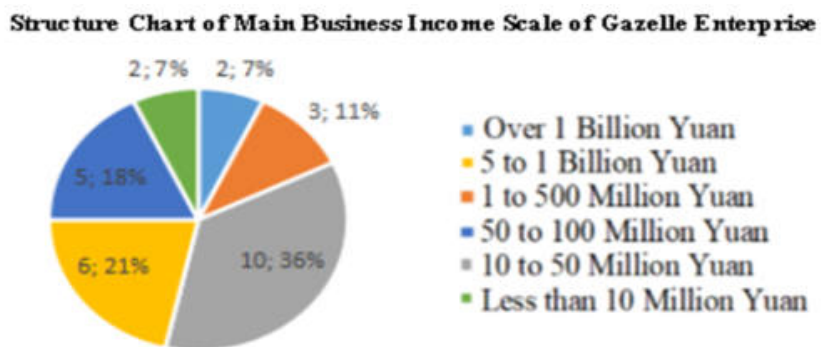

Figure 1. Chart of the Main Business Income

Figure 1 chart of business revenue scale of Taizhou Gazelle Enterprises From 2013 to 2016, the proportion of Taizhou gazelle companies which accounted for the total number of high-tech companies in Taizhou is gradually increasing, the proportion of the main business income accounted for all high-tech companies in Taizhou is also rising, see Table 3.

Table 3: The Proportion of Main Business Income of Taizhou Gazelle Companies in

High-Tech Industry.

\begin{tabular}{|l|l|l|l|l|}
\hline Year & $\begin{array}{c}\text { Gazelle Companies } \\
\text { Main Business } \\
\text { Income Total } \\
\text { (Million Yuan) }\end{array}$ & $\begin{array}{c}\text { High-Tech Industry } \\
\text { Main Business Income } \\
\text { Total (Million Yuan) }\end{array}$ & $\begin{array}{c}\text { Gazelle Companies } \\
\text { Main Business Income } \\
\text { Accounted For (\%) }\end{array}$ & $\begin{array}{c}\text { The Proportion Of } \\
\text { Gazelle Companies } \\
\text { (\%) }\end{array}$ \\
\hline $\mathbf{2 0 1 3}$ & 278904.8 & 9055670 & 3.08 & 4.97 \\
\hline $\mathbf{2 0 1 4}$ & 323699.8 & 9738286.9 & 3.32 & 6.60 \\
\hline $\mathbf{2 0 1 5}$ & 383554.9 & 9483611.2 & 4.04 & 6.64 \\
\hline $\mathbf{2 0 1 6}$ & 1164077 & 11398894.1 & 10.21 & 5.76 \\
\hline
\end{tabular}

\subsection{Industry Distribution Analysis}

At present, Taizhou Gazelle Companies are mainly distributed in the field of optical and mechanical-electrical integration, new materials, electronics and information, biology, medicine and technology. The number of Gazelle companies in each sector and the relevant financial indicators for 2016 are shown in Table 4.

Table 4: Distribution of Gazelle Enterprises in Taizhou

\begin{tabular}{|l|l|l|l|l|}
\hline Technical Field & $\begin{array}{l}\text { Number Of } \\
\text { Enterprises } \\
\text { (Home) }\end{array}$ & $\begin{array}{l}\text { Total } \\
\text { Assets } \\
\text { (Million) }\end{array}$ & $\begin{array}{l}\text { Total } \\
\text { Business Income } \\
\text { (Million Yuan) }\end{array}$ & $\begin{array}{l}\text { Total Net Profit } \\
\text { (Million Yuan) }\end{array}$ \\
\hline Electronics And Information & 3 & 37532.9 & 40948.8 & 9454.6 \\
\hline $\begin{array}{l}\text { Biological And } \\
\text { Pharmaceutical Technology }\end{array}$ & 3 & 135066.9 & 84183.3 & 22269.5 \\
\hline New Material & 5 & 144217.3 & 83855.5 & 13048.8 \\
\hline Auto-Mechatronics & 7 & 110597.3 & 67053.8 & 11476.4 \\
\hline $\begin{array}{l}\text { New Energy, High Efficiency } \\
\text { And Energy Saving }\end{array}$ & 2 & 17649 & 41449.4 & 1174.7 \\
\hline Environmental Protection & 1 & 16261.4 & 1006.2 & 36.1 \\
\hline Other & 7 & 871680.3 & 845580.1 & 48418.1 \\
\hline Total & 28 & 1333005.1 & 1164077.1 & 105878.2 \\
\hline
\end{tabular}




\subsection{R \& D Expenditure and Accounting Analysis}

In recent years, Taizhou Gazelle Companies R \& D spending on the whole to maintain a rapid growth, from 2013 which is $(704,067,000$ yuan) has increased to 2016 (194,996. 2 million yuan). The annual growth rate of 40.44\% R \& D expenditure accounts for more than $20 \%$ of the total revenue of the main business. The specific status of R \& D expenditure and share between 2013 and 2016 is shown in Table 5

Table 5: Gazelle Enterprise $R$ \& D Expenditure and Proportion

\begin{tabular}{|c|c|c|c|c|c|c|c|c|}
\hline \multirow[t]{2}{*}{ Year } & \multicolumn{2}{|c|}{$\begin{array}{l}\text { Daily technology } \\
\text { activities within the } \\
\text { enterprise expenditure }\end{array}$} & \multicolumn{2}{|c|}{$\begin{array}{l}\text { Fixed asset spending for } \\
\text { technology activities }\end{array}$} & \multicolumn{2}{|c|}{$\begin{array}{l}\text { Expenditure on } \\
\text { non-commissioned units } \\
\text { to carry out scientific } \\
\text { and technological } \\
\text { activities }\end{array}$} & \multicolumn{2}{|c|}{ Total } \\
\hline & $\begin{array}{l}\text { Amount } \\
\text { (Million) }\end{array}$ & $\begin{array}{l}\text { The } \\
\text { proportion } \\
\text { of the main } \\
\text { business } \\
\text { income } \\
(\%)\end{array}$ & $\begin{array}{l}\text { Amount } \\
\text { (million } \\
\text { ) }\end{array}$ & $\begin{array}{l}\text { The } \\
\text { proportion of } \\
\text { the main } \\
\text { business } \\
\text { income }(\%)\end{array}$ & $\begin{array}{l}\text { Amount } \\
\text { (million) }\end{array}$ & $\begin{array}{l}\text { The } \\
\text { proportion } \\
\text { of the main } \\
\text { business } \\
\text { income }(\%)\end{array}$ & $\begin{array}{l}\text { Amount } \\
\text { (million) }\end{array}$ & $\begin{array}{l}\text { The proportion } \\
\text { of the main } \\
\text { business income } \\
(\%)\end{array}$ \\
\hline 2013 & 63977.6 & 22.94 & 2035.2 & 0.73 & 4393.9 & 1.58 & 70406.7 & 25.25 \\
\hline
\end{tabular}

Table 6: Annual Distribution Of Gazelle Company's Intellectual Property Output

\begin{tabular}{|c|c|c|c|c|c|c|}
\hline \multirow[t]{2}{*}{ Year } & \multicolumn{2}{|c|}{$\begin{array}{l}\text { Number Of Patent Applications } \\
\text { Received In The Year }\end{array}$} & \multicolumn{2}{|c|}{$\begin{array}{l}\text { Number Of Patents Granted } \\
\text { For The Year }\end{array}$} & \multicolumn{2}{|c|}{$\begin{array}{l}\text { Number Of Valid Patents At } \\
\text { The End Of The Period }\end{array}$} \\
\hline & $\begin{array}{l}\text { Total } \\
\text { Number }\end{array}$ & $\begin{array}{l}\text { The Number of } \\
\text { Invention Patents }\end{array}$ & $\begin{array}{l}\text { Total } \\
\text { Number }\end{array}$ & $\begin{array}{l}\text { The Number of } \\
\text { Invention Patents }\end{array}$ & $\begin{array}{l}\text { Total } \\
\text { Number }\end{array}$ & $\begin{array}{l}\text { The Number of } \\
\text { Invention Patents }\end{array}$ \\
\hline 2013 & 1272 & 566 & 1662 & 135 & 5674 & 285 \\
\hline 2014 & 952 & 210 & 760 & 164 & 6294 & 498 \\
\hline 2015 & 601 & 160 & 1048 & 341 & 5000 & 813 \\
\hline 2016 & 984 & 283 & 805 & 362 & 5821 & 1164 \\
\hline Total & 3809 & 1219 & 4275 & 1002 & $/$ & \\
\hline
\end{tabular}

\section{Analysis}

\section{1 Analysis of Intellectual Property Output}

In the past four years, Taizhou Gazelle Companies made 3809 patent applications to the State Intellectual Property Office, including 1219 invention patent applications, a total of 4275 patents, including 1002 invention patents. As of 2016, gazelle enterprises have a valid patent number of 5821, including 1164 patents. The distribution of the specific application and authorization year is shown in Table 6. At the same time, gazelle companies also achieved a large number of other intellectual property achievements. In 2013 Taizhou gazelle company scientific research personnel published a total of 110 scientific and technological papers, with software copyright 4 . In 2014 Gazelle Company scientific researchers published a total of 9 scientific papers, then got 5 software copyright, which formed a national or industry standards. In 2015 Gazelle Company scientific researchers published a total of 36 scientific papers, then got 5 software copyright. In 2016, gazelle company scientific research personnel published a total of 35 scientific papers, then got 6 software copyright, then get 1 integrated circuit layout, with a new plant species. By the end of 2016, Gazelle Company had 199 registered trademarks, including 3 PCT registered trademarks.

\subsection{Analysis on the Application of Intellectual Property Rights}

The use of intellectual property rights includes the use of intellectual property rights by the owner himself and others. Where they use mainly direct commercialization, while others use includes licensing, transfer, Capital, Trust, pledge, etc., where licensing and transfer is the most basic, the most important way to use. Since 2013, Taizhou Gazelle Company also had a certain number of patent licensing and transfer, and to obtain a certain income, but the number and size is still limited, as shown in Table 7. 
Table 7 Intellectual Property License and Transfer Analysis of Taizhou| Gazelle Enterprises.

\begin{tabular}{|l|l|l|}
\hline Year & $\begin{array}{l}\text { Number Of Patents Transferred And } \\
\text { Licenses (Pieces) })\end{array}$ & $\begin{array}{l}\text { Patent Transfer And License Income } \\
(\mathbf{\$ 1 0 , 0 0 0})\end{array}$ \\
\hline 2013 & 24 & 31 \\
\hline 2014 & 38 & 205 \\
\hline 2015 & 0 & 0 \\
\hline 2016 & 0 & 0 \\
\hline
\end{tabular}

\subsection{Human Resources Structure Analysis}

From the data of 2013 to 2016, the overall number of Gazelle Company is increasing, and the number of returned students has remained at about 40 , accounting for about $0.5 \%$ of the total number of employees. Among them, the number of foreign experts fluctuates greatly, the maximum number of posts reached 115 people, and the minimum is only 7 people. The number of doctoral employees remained at around 50, accounting for less than $1 \%$ of the total number of employees; the number of Masters Employees remained at around 300, accounting for $6 \%$ of the total number of employees. Undergraduate and college employees accounted for more than $50 \%$ of the total number of employees. About $50 \%$ of the employees in Gazelle companies are directly or indirectly engaged in scientific and technological research and development activities. Specific staff structure proportion is shown in Table 8.

Table 8 Gazelle Corporate Employee knot

\begin{tabular}{|c|c|c|c|c|c|c|c|c|c|c|c|c|c|c|c|}
\hline \multirow[b]{2}{*}{ Year } & \multirow{2}{*}{$\begin{array}{l}\text { Total } \\
\text { Number of } \\
\text { Employee } \\
\mathrm{s}\end{array}$} & \multicolumn{2}{|c|}{\begin{tabular}{|l|} 
Students \\
Studying \\
Abroad
\end{tabular}} & \multicolumn{2}{|c|}{$\begin{array}{l}\text { Foreign } \\
\text { Experts }\end{array}$} & \multicolumn{2}{|c|}{ Doctorate } & \multicolumn{2}{|l|}{ Masters } & \multicolumn{2}{|c|}{ Undergraduate } & \multicolumn{2}{|c|}{ Junior College } & \multicolumn{2}{|c|}{$\begin{array}{l}\text { Science and } \\
\text { Technology } \\
\text { Activities }\end{array}$} \\
\hline & & \begin{tabular}{|l|} 
Number \\
of \\
Persons
\end{tabular} & $\begin{array}{l}\text { Number } \\
\text { of } \\
\text { Persons }\end{array}$ & $\begin{array}{l}\text { Numbe } \\
\text { I of of } \\
\text { Person } \\
\text { s }\end{array}$ & Perce & $\begin{array}{l}\text { Number } \\
\text { of } \\
\text { Persons }\end{array}$ & Perce-ntage & $\begin{array}{l}\text { Number } \\
\text { of } \\
\text { Persons }\end{array}$ & $\begin{array}{l}\text { Percenta } \\
\text { ge }\end{array}$ & $\begin{array}{l}\text { Number } \\
\text { Persons }\end{array}$ & Percentage & $\begin{array}{l}\text { Number } \\
\text { of } \\
\text { Persons }\end{array}$ & Percentage & $\begin{array}{l}\text { Number } \\
\text { of } \\
\text { Persons }\end{array}$ & Percentage \\
\hline 2013 & 5612 & 30 & $0.53 \%$ & 20 & $0.36 \%$ & 37 & $0.66 \%$ & 379 & $6.75 \%$ & 1621 & $28.89 \%$ & 1428 & $25.45 \%$ & 3098 & $55.20 \%$ \\
\hline 2014 & 6901 & 34 & $0.49 \%$ & 115 & $1.67 \%$ & 65 & $0.94 \%$ & 348 & $5.04 \%$ & 1968 & $28.52 \%$ & 1599 & $23.17 \%$ & 3389 & $49.11 \%$ \\
\hline 2015 & 8394 & 44 & $0.52 \%$ & 82 & $0.98 \%$ & 57 & $0.68 \%$ & 513 & $6.11 \%$ & 2568 & $30.59 \%$ & 2019 & $24.05 \%$ & 4192 & $49.94 \%$ \\
\hline 2016 & 9682 & 42 & $0.43 \%$ & 7 & $0.07 \%$ & 42 & $0.43 \%$ & 336 & $3.47 \%$ & 1811 & $18.70 \%$ & 2386 & $24.64 \%$ & 2756 & $28.47 \%$ \\
\hline
\end{tabular}

\subsection{Development Capacity Analysis}

Taizhou gazelle company Development ability is mainly to investigate the new product market appeal, 2013 to 2016 gazelle company new product annual output value increase in more than $100 \%$, sales and export growth are also high, indicating that Taizhou gazelle company's new product research and development ability, has developed a great potential and a great force for economic development. The annual output value of new products, sales, exports and increase can be seen specifically in Table 9.

Table 9: New Product Output Value, Sales, Export Value and Increase of Taizhou Gazelle Enterprise

\begin{tabular}{|l|l|l|l|l|l|l|}
\hline Year & $\begin{array}{l}\text { New Product Output Year-On-Year } \\
\text { Value (Million Yuan) } \\
\text { Growth (\%) }\end{array}$ & $\begin{array}{l}\text { New Product Sales } \\
\text { Revenue } \\
\text { Yuan) }\end{array}$ & $\begin{array}{l}\text { Year-On-Year } \\
\text { (Million }\end{array}$ & $\begin{array}{l}\text { New Product Export } \\
\text { Growth (\%) }\end{array}$ & $\begin{array}{l}\text { Year-On-Year } \\
\text { Growth (Million) }\end{array}$ \\
\hline 2013 & 49382.1 & $/$ & 40639.3 & $/$ & 797 & \\
\hline 2014 & 123416.6 & 149.92 & 122068.9 & 200.37 & 4133.4 & 418.62 \\
\hline 2015 & 275648 & 123.35 & 185558.6 & 52.01 & 6850.2 & 65.73 \\
\hline 2016 & 790467.3 & 186.77 & 264147.5 & 42.35 & 47367.2 & 591.47 \\
\hline
\end{tabular}

\subsection{Financing Channel Analysis}

In 28 gazelle companies, in addition to Zhejiang Xiantong Rubber And Plastic Co., Ltd. listed on the Shanghai Stock Exchange, the others are non-listed entities. Financing channels are relatively simple, in addition to Zhejiang shengtai Defense Technology Co., Ltd., Zhejiang Youyi Medical Equipment Co., Ltd., Zhejiang Luhu Automobile Co., Ltd. has a certain amount of venture capital, and other companies have access to funds through the traditional way of financing. The overall asset-liability ratio of Gazelle companies was $64.85 \%$ in $2013,68.95 \%$ in 2014 , $67.61 \%$ in 2015 and $67.48 \%$ in 2016.It can be seen that the overall balance-of-assets ratio of Gazelle company is still high, and the balance-of-assets ratio needs to be reduced through a combination of various financing methods in order to control financial risks. 


\subsection{Support Policy Analysis}

At present, the local government of Taizhou Gazelle Company's support is mainly reflected in three aspects: first, the government subsidies, second, tax relief, third, other aspects. From 2013 to 2016, government grants and tax breaks for Gazelle companies are summarized in Table 10.

Table 10 Gazelle Corporate Government Subsidies and Tax Breaks

\begin{tabular}{|l|l|l|l|l|l|l|}
\hline Year & $\begin{array}{l}\text { Government subsidy } \\
\text { income }(\$ 10,000)\end{array}$ & Increase & $\begin{array}{l}\text { VAT exemption } \\
\text { (Million) }\end{array}$ & Increase & $\begin{array}{l}\text { Income tax relief } \\
\text { (Million) }\end{array}$ & Increase \\
\hline 2013 & 34550.9 & & 650.8 & & 1662.8 & \\
\hline 2014 & 9848.5 & $-71.4 \%$ & 498.2 & $23.4 \%$ & 2825.8 & $69.9 \%$ \\
\hline 2015 & 7422.0 & $-24.6 \%$ & 464.9 & $-6.7 \%$ & 5842.5 & $106.7 \%$ \\
\hline 2016 & 14684.8 & $97.8 \%$ & 2360.5 & $407.7 \%$ & 8327.0 & $42.5 \%$ \\
\hline
\end{tabular}

General Taizhou gazelle companies development status is not difficult to find, the rapid development of these companies, the increasing number of companies, increasing growth rate business income, net profit and its growth rate, taxes paid and its growth rate, research and development investment and output performance is much higher than the average level of high-tech companies. However, at the same time, we must also clearly recognize that Taizhou gazelle companies cultivation and development, domestic economic developed areas, compared with the province of Hangzhou, Ningbo, is a significant gap: on the one hand, Taizhou gazelle companies total is still small, and their single strength gap is also very large; secondly, gazelle companies economic contribution to the region there is not worth it as compared to the above mentioned provinces.

\section{Factors Affecting the Rapid Growth of Gazelle Companies.}

On the basis of reviewing the relevant literatures on gazelle companies both home and abroad, findings summarized the main factors affecting the rapid development of Gazelle companies which are Human Resource factors, research and development investment factors, financing capacity factors, entrepreneurial innovation and cultural atmosphere factors, policy support factors.

4.1 Human Resource factors: Human resources is the most active and creative factor to consider in every sector of the economy of which Gazelle companies are of no exception, the human resource factor is particularly important to them as well. First of all, the Gazelle companies should have the characteristic of human resource structure which is different from the traditional companies because for the traditional companies, usually have the first-line manufacturing or service workers accounted for relatively high percentage, the average age of employees is higher and the average level of education may be lower; but for Gazelle which directly engages in scientific and technological research and development the staff accounts for a higher proportion of the general, and the National Thousand Plan, provincial Thousand Plan and others. In addition, the average age of employees in Gazelle companies is lower and the average level of education is higher. Also, gazelle companies may adopt a more flexible management model for high-level talents.

4.2 R \& D Investment: In an era of mass entrepreneurship and innovation, R \& D investment is crucial for any business. But most company's R \& D investment accounts for the proportion of sales revenue which is very different from the general traditional companies whose R \& D investment accounts for less than $3 \%$ of the annual sales revenue. For Gazelle companies, huge ongoing R \& D investment is essential and from the Taizhou gazelle companies $\mathrm{R} \& \mathrm{D}$ investment accounts for the proportion of annual sales revenue, the average annual sales revenue is almost at more than $10 \%$. Only a large number of $\mathrm{R} \& \mathrm{D}$ investment is likely to continue to introduce new technologies, new knowledge, and new products to keep the companies in business.

4.3 Investment and Financing Environment: A good investment and financing service environment can well solve the huge continuous R \& D fund demand of Gazelle companies .And Gazelle Corporate financing needs have its own characteristics, it is usually dominated by equity, intellectual property financing, its long-term debt ratio and cash dividend payout ratio is low. For a long time there is a serious information asymmetry between the small and medium-sized scientific and technological companies and financial institutions. On one hand, commercial bank loans have higher requirements on the credit level of the company's, fixed assets, guarantees and so on; on the other hand, for high-tech companies, especially small gazelle companies basically cannot meet these conditions, so they are often very small opportunities to obtain financial support from commercial financial institutions. A more flexible and relaxed investment and financing environment is essential for the healthy development of Gazelle companies. At home and abroad, whether it is the United States Silicon Valley, or China Zhongguancun, Gazelle Corporate agglomeration area is often also the most active venture capital and an angel investment area.

4.4 Entrepreneurship and Innovation Cultural Atmosphere Factors: In general, most of Gazelle companies belong to the field of high-tech industry. In these areas, they dare to be good at the acceptance of trial and error of the innovation culture which more is prevalent, the respect for knowledge, advocating innovation, entrepreneurship 
and rich values that deeply rooted in the hearts of the people. The traditional work attitude of seeking stability and seeking ease makes it difficult to have a market. "Encourage entrepreneurship, tolerate failure, aim at the leading" is an important connotation of Zhongguancun entrepreneurship culture, it is in this culture of entrepreneurship and innovation under the influence, Lenovo explore out of a "relying on science and technology to create wealth" of innovation, from only 11 employees 200,000 yuan assets of small "gazelle" developed into the world's third largest PC manufacturers.

4.5 Policy support factors: Gazelle companies that are recently established, "sub " is small, in the face of a complex market environment, its own power is insignificant, it is difficult to effectively deal with. The government can and should play an active role in improving the adaptability of Gazelle companies. The government can provide policy support in the areas of Finance, Taxation, Talent, Science and technology intermediary services, intellectual property protection, etc.

\section{Domestic and Foreign Policy Experience and Taizhou Support Policy System Construction.}

Silicon Valley in the United States since 1994, "gazelle number of companies" as an important indicator of the economic prosperity of Silicon Valley .The organization for Economic Co-operation and Development (OECD) has identified gazelle rates as one of the important statistical indicators of regional economic development, and has continued to track the development of "Gazelle companies " since 2011.China first in 2003 in Beijing Zhongguancun Science and Technology Park implementation of "Gazelle plan", then Wuhan, Suzhou, Ningbo, Hangzhou, Wuxi, Shenzhen have launched for "Gazelle companies " policy. Zhongguancun as one of the most active region of the global gazelle companies, "high-tech entrepreneurship + Global Link" is the development of Zhongguancun "gazelle" the biggest feature, through the construction of a sound ecological industrial cluster which gave birth to a large number of vibrant "gazelle companies"; Wuxi through the improvement of industrial organization also provided development support for the "Gazelle companies". Strengthening the ability of industrial organization, focusing on the development of key emerging industries "is the reason for the development of Wuxi"gazelle" features. Ningbo to create "angel" of the city, to cultivate "gazelle". Relying on the private economy, encourage entrepreneurship, support for emerging industries to the development of "Gazelle companies" are the characteristics of Ningbo gazelle. Nine provinces including Wuhan through tens of millions of square meters of incubators to stimulate "gazelle" vitality. Business incubation is Wuhan Development "gazelle" main organization's mode, and through amplification photoelectron industry took advantage leading the emerging industry cluster cultivation which became Wuhan Development "gazelle" in an important way; reform and opening up most front of Shenzhen insisted for market oriented operation to strategize the transformation for industry. To polymerization science education intellectual resources for power, overall cultivation emerging industry cluster, promotion enterprise competition is the development of Suzhou "gazelle" features; Hangzhou, one of the heaven on Earth, is developing a gazelle company by accelerating its transition to a new economy and creating a livable and entrepreneurial Paradise. On the basis of reviewing the experience of developing gazelle companies at home and abroad, we will like proposed a policy system to support the development of Gazelle Companies in Taizhou can lead to the economic fission.

(A) To speed up the design and implementation of Taizhou "gazelle plan "as soon as possible. Taizhou gazelle plan should be based on Taizhou economic and social development in the 13th five-year plan, based on the actual development of Taizhou industry which design small and micro enterprises - gazelle companies - large companies---industry leading companies_listed enterprises " gradient cultivation mechanism, from economic development, scientific and technological innovation, sustainable development and other aspects of building eligibility indicators, free, fair and open for the Gazelle company cultivation and development into the innovation County Urban Construction assessment.

(B) Grasp the Taizhou small and micro enterprises financial service reform innovation pilot area opportunities, in Taizhou Local Government guidance and promotion should actively implement Taizhou "gazelle program" credit rating evaluation work, establish Taizhou "gazelle program" credit risk fund, support Taizhou "gazelle company" formation mutual guarantee Cooperation Organization, promote its holding group letter and financing. To build a good financial ecological environment for the development of the service desk gazelle companies, and to take a characteristic of the Taizhou gazelle Enterprise Financial Services "Insurance loan linkage" road.

(C) Relying on Taizhou 500 elite plan, to increase the growth of Taizhou gazelle companies intellectual support. Research and carding Taizhou gazelle company Development presents urgent need for high-end innovation and entrepreneurship talent, relying on Taizhou 500 elite program funded projects, actively attract and gather domestic and foreign high-end leading talent (national Thousand Plan, Zhejiang province Thousand Plan talent) to partake in the innovation and entrepreneurship talent hunt. Establishment of a talent club for gazelle programm relevant, do a good job gazelle talent logistics services, so that they can feel at ease to enjoy the work life in Taizhou.

(D) Strengthening the Gazelle enterprise-led collaborative innovation. Implementation by the Gazelle enterprise led, agglomeration of Tsinghua Yangtze River Delta Research Institute, Zhejiang Taizhou Research Institute, 
Taizhou college, Taizhou Vocational College of Science and technology, Taizhou vocational college and other innovative resource elements should actively carry out the Gazelle scientific and technological project Research Program, build a laboratory or technology center, share experimental data, share the dividend of innovation, and promotion of gazelle companies in the region.

(E) Strengthening the assessment of the effectiveness of public policies gazelle program. Through the evaluation of the main diversity, the evaluation of the time dynamic, the evaluation of the content of the multi-angle, the assessment results of the serious use of such measures to do real gazelle plan public policy effect assessment, to ensure that the Gazelle public policy plan works effectively to achieve its purpose.

(F) Emphasis on the theoretical research of the cultivation and development of Gazelle companies should be actively designed to speed up the implementation of Taizhou gazelle program at the same time, relying on the Taizhou Municipal Government Policy Research Office, Taizhou college, Zhejiang University Taizhou Research Institute and other theoretical research institutions and organizations to actively carry out the cultivation and development of Gazelle company theory, both at home and abroad. Gazelle company development should track theoretical research results, refine it but also in a timely manner to summarize the unique approach to inductive Taizhou gazelle program, the formation of Taizhou experience collection publishing to expand the impact.

\section{References}

[1]Sun Hongyan. "Gazelle Enterprise" Rapid Growth Factors Analysis-Take Zhongguancun as an Example [J] Economics and Management 2008, 10, (10): 93-97.

[2] Young Winley. This Is the Default Tomcat Home Page. China High-Tech Industry Herald, 2006-05-29.

[3] Hu Haiqing, Li Hao. Accelerator Support, Environmental Dynamics and Breakthrough Innovation in Gazelle Enterprises [J] R \& D Management, 2015, 12 (12): 47-56.

[4]Zhang Libin. Problems and Countermeasures for the Development of Gazelle Enterprises In Wuhan East Lake National Demonstration Zone of Independent Innovation [J] Green Science and Technology, 2012, 4 (4):233236.

[5] Dong Bi Juan. Gazelle Enterprise: Looking Forward to the Wider "Steppe" [N] Economic Daily, 2016-8-22. 